\title{
CUSTOS DE TRANSAÇÃO NO MERCADO DO LEITE DA AGRICULTURA FAMILIAR NO MUNICÍPIO DE CAIÇARA - RS
}

\section{TRANSACTION COSTS IN FAMILY FARM MILK MARKET IN THE MUNICIPALITY OF CAIÇARA, RIO GRANDE DO SUL STATE}

\author{
Claudia Maria Prudêncio de Mera \\ Docente do Mestrado profissional em Desenvolvimento Rural e do Programa de Pós-Graduação em \\ Práticas socioculturais e desenvolvimento social da Universidade de Cruz Alta \\ cmera@unicruz.edu.br \\ Angelo Paloschi \\ Administrador e Mestre em Desenvolvimento Rural pela Universidade de Cruz Alta \\ angelo.paloschi@iffarroupilha.edu.br \\ Tamara Silvana Menuzzi Diverio \\ Docente do Mestrado Profissional em Deenvolvimento Rural da Universidade de Cruz Alta \\ tdiverio@unicruz.edu.br
}

\section{Resumo}

As transformações e adaptações no ambiente institucional da cadeia produtiva do leite interferem diretamente no contexto comercial, organizacional e estrutural do setor, e vêm propiciando a necessidade do produtor se especializar e realizar investimentos visando dar continuidade no desenvolvimento da atividade leiteira, muitas vezes sem conhecer o contexto do mercado no qual está inserido, gerando custos de transação. Esta pesquisa analisou os custos de transação que incidem nas relações entre agricultores familiares e os agentes do mercado do leite no município de Caiçara-RS. A abordagem teórica baseouse na Nova Economia Institucional (NEI) e, mais especificamente, na abordagem da Economia dos Custos de Transação. Quanto aos aspectos metodológicos, foi realizada uma pesquisa descritiva com dados quantitativos, tendo como estudo de caso o município de Caiçara. Este município possui uma expressiva produção de leite, contudo não existem indústrias processadoras que realizem o beneficiamento do produto, fazendo com que toda a produção seja comercializada por empresas de munícipios vizinhos e de outras regiões do Estado. Foram coletados dados através de questionários aplicados junto a 174 agricultores familiares que atuam na atividade leiteira do município, entre os meses de setembro e outubro de 2017. Destaca-se que, com o desenvolvimento deste trabalho, os principais atributos das transações, como o oportunismo, a frequência e a confiança, apresentaram índices baixos, limitando, assim, os custos de transação. Já a especificidade dos ativos e incertezas apresentaram altos índices.

Palavras-chaves: Agricultura. Familiar. Leite. Custos. Transação. 


\begin{abstract}
The present study analyzed the main milk market transaction costs incurred in the relationships between rural producers and processing companies in the municipality of Caiçara, in the state of Rio Grande do Sul. Our theoretical approach processes using the New Institutional Economics (NIE) and, more specifically, the Transaction Cost Economics. As for the methodological aspects, it is an exploratory research, and its case study is the municipality of Caiçara. This town has a large milk production. However, there are no local processing companies performing the product improvement. This implies that its production ends up being traded with companies in the region. Data were collected through questionnaires applied to 174 family farmers working in dairy farming of Caiçara, in order to identify the main transaction costs inherent to this activity. It was possible to identify the age range of family farmers that participated in the research and their low level of school education. Milk market in Caiçara is characterized as a competitive oligopsony consisting of eight dairy companies. It should be noted that it was possible with this paper to identify the main attributes of those transactions, where opportunism, frequency, and confidence presented low rates, limiting transaction costs therefore. Regarding the specificity of assets and uncertainties, they presented high rates mainly due to the lack of knowledge on milk market by the farmers and alternatives that can be developed with the equipment and dairy cattle used in the sector.
\end{abstract}

Keywords: Agriculture. Familiar. Milk. Costs. Transaction.

\title{
Introdução
}

$\mathrm{Na}$ agricultura familiar a produção de leite começou a se desenvolver por vários fatores, sendo um dos principais a produção para o próprio consumo da família e destinando o excedente para a comercialização ou processamento. Assim, a atividade leiteira foi ganhando importância econômica na região, pois além de servir como alimentação, permitiu a criação de uma fonte de renda mensal e, em muitas propriedades, a produção de leite foi substituindo o lugar de produções safristas.

As transformações e adaptações no ambiente institucional da cadeia produtiva do leite interferem diretamente no contexto comercial, organizacional e estrutural do setor, e vêm causando a necessidade de o produtor se especializar e realizar investimentos para dar continuidade no desenvolvimento da atividade leiteira, muitas vezes sem conhecer o contexto de mercado no qual está inserido, gerando custos de transação. Para a Nova Economia Institucional (NEI) os custos de transação são aqueles com os quais os agentes se defrontam toda vez que necessitam recorrer ao mercado, como os custos de negociar, redigir e garantir o cumprimento de um contrato formal ou informal. 
Para Schubert (2012), os mercados lácteos estão se especializando, concentrandose em alguns elos e diversificando-se em outros, cujo custo de transação está relacionado ao comportamento dos agentes do mercado do leite, às relações de poder, às formas de inserção nos mercados, e à concorrência por matéria prima. Fatores que impactam de forma significativa nos preços pagos e nas estruturas de mercado da cadeia produtiva do leite.

$\mathrm{Na}$ avaliação dos custos de transação relacionados ao mercado do leite, Casali e Marion Filho (2012) afirmam que existe uma relação de dependência entre os agentes, o que contribui para reduzir o grau de incerteza. Entretanto, ela é inversamente relacionada à escala de produção, pois os grandes agricultores são disputados pelos laticínios e a pequena produção é refém de um número reduzido de compradores, que em sua grande maioria são cooperativas.

No estudo realizado no estado do Rio Grande do Sul sobre os custos de transação na cadeia produtiva do leite, Breitenbach (2012) observou que a concorrência gera modificações no comportamento dos agentes e o aumento nos custos de transação, ambos caracterizados pela maior frequência nas transações, aumento da incerteza e do oportunismo.

Já no município de Caiçara, região noroeste do Rio Grande do Sul, estão estabelecidos 1.418 agricultores, sendo que 316 agricultores desenvolvem a atividade leiteira, e estão caraterizados como agricultores familiares, segundo IBGE (2006). A comercialização do leite ocorre com empresas de munícipios vizinhos e outras regiões do Estado (PREFEITURA MUNICIPAL DE CAIÇARA/RS, 2016).

Desta forma, a pesquisa procurou analisar os custos de transação incorridos nas relações entre agricultores familiares e agentes no mercado do leite no município de Caiçara-RS. A seguir apresenta-se os aspectos metodológicos da pesquisa.

\section{Aspectos metodológicos da pesquisa}

O foco empírico da pesquisa é o município de Caiçara, localizado na região Noroeste do Estado do Rio Grande do Sul, pertencente à Microrregião de Frederico Westphalen. Possui uma área de 189,203 quilômetros quadrados, fazendo divisa fluvial com o estado de Santa Catarina (IBGE, 2006). Tem uma população de 5.071 habitantes, 
destes $60 \%$ residem no meio rural, sendo que 316 agricultores atuam na atividade leiteira e são considerados agricultores familiares, conforme informações da Prefeitura Municipal de Caiçara/RS (2016).

$\mathrm{Na}$ economia do município de Caiçara, a produção de fumo destaca-se como a principal atividade agrícola desenvolvida, sendo que aproximadamente 750 estabelecimentos rurais atuam na atividade. Devido às altas produções deste produto, Caiçara foi conhecida por muitos anos como a Capital Regional do Fumo, porém devido às restrições e leis impostas à atividade nos últimos anos, a área plantada vem diminuindo gradativamente (DEGREGORI et al,2015). Além do fumo, destaca-se a bovinocultura de leite e corte e a suinocultura, seguidas pelas produções de milho, soja e feijão.

A coleta de dados empíricos, através da pesquisa de campo foi realizada nos meses de setembro e outubro de 2017, com 174 agricultores familiares que desenvolvem a atividade leiteira no município de Caiçara.

A determinação da amostra se deu através da adoção de um erro amostral de 5\%, um nível de confiança de 95\%, que são valores seguros usualmente adotados em pesquisas. Para o desenvolvimento do cálculo amostral foi utilizado como referência Timm (2012).

$$
\begin{gathered}
n=\frac{N \cdot Z^{2} \cdot p \cdot(1-p)}{\mathrm{Z}^{2} \cdot \mathrm{p} \cdot(1-\mathrm{p})+e^{2} \cdot(N-1)} \\
n=\frac{316 \cdot(1 \cdot 96)^{2} \cdot 0,5 \cdot(1-0,5)}{(1,96)^{2} \cdot 0,5 \cdot(1-0,5)+(0,05)^{2} \cdot(316-1)} \\
n=\frac{316 \cdot 3,8416 \cdot 0,5 \cdot 0,5}{3,8416 \cdot 0,5 \cdot 0,5+0,0025 \cdot 315} \\
n=\frac{303,486}{0,9604+0,7875} \\
n=\frac{303,486}{1,7479}=174
\end{gathered}
$$

Onde:

$\mathrm{n}=$ amostra calculada

$\mathrm{N}$ = população

$\mathrm{Z}=$ variável normal padronizada associada ao nível de confiança $(1,96)$

$\mathrm{p}=$ verdadeira probabilidade do evento $(50 \%)$

$\mathrm{e}=$ erro amostral $(5 \%)$ 
Para a escolha da categoria de agricultor familiar, foi utilizado o conceito de acordo com a Lei ${ }^{\circ} 11.326$, de 24 de julho de 2006:

\begin{abstract}
Art. $3^{\circ}$ Para os efeitos desta Lei considera-se agricultor familiar e empreendedor familiar rural aquele que pratica atividades no meio rural, atendendo, aos seguintes requisitos:

I - não detenha, a qualquer título, área maior do que 4 (quatro) módulos fiscais; II - utilize predominantemente mão de obra da própria família nas atividades econômicas do seu estabelecimento ou empreendimento;

III - tenha renda familiar predominantemente originada de atividades econômicas vinculadas ao próprio estabelecimento ou empreendimento; IV - dirija seu estabelecimento ou empreendimento com sua família. (BRASIL, 2006).
\end{abstract}

Adotaram-se os seguintes procedimentos para aplicação do questionário: visitas do pesquisador em 156 propriedades rurais no município de Caiçara. Cada aplicação do questionário efetuada com o agricultor tinha duração média de 20 minutos. A outra forma de aplicação do questionário foi através do Sindicato dos Trabalhadores Rurais de Caiçara, o qual colaborou com a aplicação de sete questionários, bem como a Cooperativa de Crédito Rural com Interação Solidária (CRESOL) unidade de Caiçara, com a aplicação de oito questionários, e a Agropecuária Agrovital, que aplicou três questionários. Os colaboradores entregaram os questionários aos agricultores para que os mesmos respondessem as questões.

Para a análise das respostas foi utilizado o Microsoft Excel 2010. Quanto às respostas dos agricultores nas variáveis que compõem os custos de transação, foi utilizada a escala de diferencial semântico, que de acordo com Schubert (2012) tem o objetivo de compreender significados conotativos, na qual demonstram elevados índices de dificuldade de exposição. Desta forma, a escala utilizada oscila de 0 a 7 , mostrando o nível de aproximação do participante da pesquisa entre o extremo e seu oposto, sendo utilizados nas questões os indicadores Pouco e Muito/Dificilmente e Facilmente/PoucoFrequente e Muito-Frequente/Não Confiável e Confiável.

Para a pesquisa de campo foi utilizada à técnica de amostra não probabilística por conveniência. Esta técnica consiste na seleção de uma amostra da população que seja acessível e que se dispuser a participar da pesquisa. A pesquisa foi encaminhada para apreciação ao Comitê de Ética em Pesquisa - CEP, possuindo o número de registro CAAE 70843617.9.0000.5322 sendo aprovado em 25 de agosto de 2017. 
Variáveis que compõem os custos de transação na atividade leiteira no município de Caiçara-RS, de acordo com a Nova Economia Institucional

Neste item dispõe-se das bases teóricas que estabeleceram as estruturas necessárias para fundamentar o trabalho desenvolvido, objetivando um debate entre as interfaces da base teórica com o campo empírico deste estudo. Posteriormente, serão abordadas as variáveis que constituem os custos de transação, sendo elas a Incerteza, o oportunismo, as especificidades dos Ativos, a frequência e a confiança.

\section{A Nova Economia Institucional - NEI}

De acordo com Tomé e Schmidt (2016, p. 98), os primeiros passos da Nova Economia Institucional "tiveram início nos anos 1930 com um grupo interdisciplinar de estudiosos estimulados pelas discussões sobre questões de políticas públicas".

Nesse período, um dos principais autores que organizou e propagou a abordagem da NEI foi Roald Coase (1937), trazendo um importante debate sobre incertezas e sua influência nas decisões de grupos e de organizações em decidir o que fazer e como fazer frente a determinadas situações de mercado. Outra importante contribuição para a consolidação da NEI está em Douglass North, que traz para o debate as análises sobre as instituições através dos tempos, dos direitos de propriedade e as relações entre Estado e Sociedade, sendo esse o espaço no qual se constituem os ambientes institucionais propriamente ditos.

Segundo North (1991), as Instituições são as restrições humanas legadas que estruturam as interações políticas e sociais. Correspondem ao sistema de normas formais, restrições informais e sistemas de controle que regulam a interação humana na sociedade. Deste modo, o autor afirma que os ambientes institucionais são definidos pelo conjunto de regras políticas, sociais e legais que estabelecem as estruturas para a produção, troca e distribuição na economia. Entende a organização enquanto um conjunto de indivíduos dedicados a alguma atividade com um determinado objetivo. De modo que as organizações devam ser entendidas e estudadas devido à constante relação estabelecida entre ambiente e organização, na medida em que há um processo contínuo de ação e reação entre a organização e seu ambiente institucional. 
Segundo Bueno (2004), a principal ideia da Nova Economia Institucional é que as instituições de uma sociedade são formadas através de importantes processos de negociações por meio de indivíduos ou através de grupos com o intuito de minimizar os custos de transações.

Os autores Rosa, Vailatti e Vicente (2017, p. 102) entendem o ambiente institucional "como um conjunto de regras sociais, legais e políticas, que estabelecem as bases da produção, troca e distribuição, exercendo uma grande influência no comportamento das organizações econômicas". Eles destacam que as organizações econômicas são constituídas por grupos de indivíduos que se comprometem com um propósito em comum a fim de atingir seus objetivos através de transações realizadas com as instituições que podem proporcionar a obtenção das metas determinados pelos envolvidos.

De acordo com Breitenbach (2012), o ambiente institucional é o conjunto dos direitos políticos, sociais e jurídicos, e das regras que estabelecem a base para a produção, troca e distribuição de produtos. Desta forma, a autora considera que as instituições são estabelecidas de acordo com as regras formais, como constituições, leis e direitos de propriedade, sendo também formadas por regras informais, como sanções, tabus, costumes, tradições e códigos de conduta.

Seguindo essa linha de pensamento, os autores Figueiredo, Mendes e Michels (2009) afirmam que o ambiente institucional é o nível analítico que compõe a NEI, identificado através do estudo macro institucional, de fundamentos como leis, valores e aprendizado, sem desvincular as racionalidades.

Assim, de acordo com Schubert (2012), para um ambiente institucional não causar amplos custos aos agentes de uma negociação, é necessário que esteja estável através da redução das incertezas, por meio da sincronização e de neutralidade de informações contidas pelos envolvidos em uma transação.

Dessa forma, toda operação que negociar direitos de propriedade pode ser caracterizada como uma transação. Já Zylbersztajn (1995, p. 16) considera "que as transações ocorrem em um ambiente institucional estruturado e que as instituições não são neutras". Desse modo, o autor destaca que as instituições de uma negociação interferem nos custos de transação. 
Pode-se dizer que os estudiosos da NEI indicam que a principal questão relacionada com a organização econômica se refere ao problema da contratação. Consideram que há custos antes, durante e após a uma negociação, denominados de custos de transação.

\section{Economia dos Custos de Transação - ECT}

A parte da economia que trata dos custos de transação teve origem com os trabalhos de Ronald Coase (1937). Segundo o autor, os custos de transação decorrem fundamentalmente da tentativa de obtenção das informações de mercado, na medida em que o autor pressupõe este como um procedimento particular de cada organização, da negociação e do estabelecimento dos contratos, incluindo, nesse caso, custos de monitoramento das cláusulas acordadas.

Seguindo essa linha de pensamento, Williamson (1985, p. 55) aponta que os custos de transação são principalmente os custos ex-ante tanto em um contrato formal ou informal, como também os custos ex-post.

Os custos ex-ante, são:

- Custos relacionados com a formalização da transação.

- Custos de localização de clientes e fornecedores.

- Custos relacionados com o processo de negociação.

- Custos relacionados ao estabelecimento de salvaguardas necessárias a todo e qualquer acordo.

- Custos para ensinar a produzir o que se necessita.

Os custos ex-post, são:

- Custos relacionados à má adaptação das transações ao acordo.

- Custos das negociações em que se incorrem quando há esforços para corrigir o estabelecido.

- Custos associados ao estabelecimento e manutenção das estruturas de governança.

- Custos de manutenção dos compromissos estabelecidos formal ou informalmente.

Segundo Breitenbach (2012), os custos de transação têm uma relação direta com o arranjo de uma cadeia produtiva, pois estes condicionam a ação dos agentes em busca de maior ou menor grau de coordenação em vista dos custos embutidos nas negociações entre as partes.

Nos próximos itens analisar-se-á a obtenção de informações do mercado de leite pelos agentes do Município de Caiçara, investigando as relações de confiança do 
agricultor familiar que atua na produção leiteira aos órgãos públicos e privados diretamente ligados à atividade.

\section{Incertezas}

Quanto às incertezas, para Arbage (2004) são classificadas em três naturezas: incerteza primária, incerteza secundária e conductista. São conceituadas do seguinte modo:

\footnotetext{
- Incerteza primária. Este tipo se refere às informações relacionadas às alterações no âmbito institucional e organizacional como, por exemplo, alterações em determinados padrões comportamentais dos consumidores ou mesmo modificação de leis que apresentam influência direta ou indireta na transação em questão.

- Incerteza secundária. Este aspecto se caracteriza pelo desconhecimento, geralmente por falta de comunicação adequada, de elementos de natureza estratégica importantes para os agentes que se relacionam em torno de uma transação. Neste caso, o que ocorre são falhas na troca de informações entre os agentes, de sorte que os parceiros comerciais não sabem exatamente onde os outros pretendem chegar nem os seus porquês.

- Incerteza conductista. É um subtipo da categoria analítica vinculada aos aspectos estratégicos e que se relaciona com o oportunismo. É a incerteza que decorre do desconhecimento do comportamento dos parceiros com os quais uma determinada organização realiza suas transações com certa frequência. (ARBAGE, 2004, p. 79).
}

Para Breitenbach (2012), a incerteza é uma propriedade das transações que possui influência sobre as características das instituições, sendo que varia entre a capacidade de os agentes pressuporem situações futuras, podendo estimular a inovação de formas contratuais mais flexíveis, que baseiam a relação entre os agentes envolvidos em uma transação.

Dessa forma, a referida autora considera que tal flexibilidade é embasada em uma situação de incertezas. O surgimento de ocorrências não previstas antes da consolidação de um contrato provoca a necessidade de mecanismos que viabilizem a adaptação da ligação entre os participantes de uma negociação (BREITENBACH, 2012).

Assim, considera-se que a incerteza influencia na tomada de decisões dos agentes envolvidos em uma transação, fazendo com que os mesmos modifiquem posturas a fim de tomar decisões à frente de determinadas situações. Schubert (2012) destaca que as incertezas possuem significativas características em mercados de economias abertas, porque ocasionam motivações e possibilidades de benefícios e acréscimo de lucros, maior 
competitividade, busca por inovações e maior qualidade nos serviços e produtos, ocasionando a redução dos preços aos consumidores.

Nesta pesquisa, a variável incerteza concentrou-se sobre as informações no preço que é pago pelo litro do leite e à obtenção de informações repassadas pelos laticínios quanto a estratégias futuras do mercado leiteiro. Os dados do Quadro 1 mostram que a maior parte dos agricultores $(59,77 \%)$ informou que possuem pouco conhecimento sobre o assunto, gerando incertezas quanto a atuação neste mercado. No entanto, os agricultores que relataram ter algum conhecimento recebem essas informações que são repassadas através de visitas de um representante do laticínio à propriedade rural ou através de informativos encaminhados aos agricultores.

Quadro 1 - Escala sobre informações sobre o preço do leite

\begin{tabular}{|c|c|c|}
\hline Escala de diferencial & Número de agricultores & Porcentagem \\
\hline Pouco & & $59,77 \%$ \\
\hline 0 & 104 & $2,87 \%$ \\
\hline 1 & 5 & $5,17 \%$ \\
\hline 2 & 9 & $2,87 \%$ \\
\hline 3 & 5 & $6,90 \%$ \\
\hline 5 & 12 & $9,20 \%$ \\
\hline 6 & 16 & $1,72 \%$ \\
\hline 7 & 3 & $11,50 \%$ \\
\hline Muito & 20 & \\
\hline
\end{tabular}

Fonte: Pesquisa de campo, 2017.

Buscando minimizar as incertezas sobre o mercado, os agricultores entram em contato com o laticínio, grande parte das vezes por telefone, a fim de obterem informações do valor que irão receber pelo litro de leite. Porém, na maioria das vezes, a resposta, conforme relato dos respondentes, que é dada ao agricultor é apenas a informação que o leite está passando desvalorização ou por valorização, dificultando com que o agricultor tenha conhecimento do valor exato que irá receber por sua produção.

\section{Oportunismo}

O oportunismo é identificado como uma condição de natureza comportamental, na qual os agentes de uma negociação agem visando a seus interesses próprios sem colaborar na formação dos termos de contrato. Esse comportamento ocorre devido, principalmente à assimetria no domínio das informações, na qual um dos envolvidos da 
negociação pode levar vantagem para si, decorrente em grande parte do desconhecimento da outra parte contratante.

Oportunismo é o outro pressuposto comportamental, sendo um conceito que resulta da ação dos indivíduos na busca do seu auto-interesse. Entretanto o auto-interesse pode ser buscado de maneira não oportunista. Oportunismo parte de um princípio de jogo não cooperativo, onde a informação que um agente possa ter sobre a realidade não acessível a outro agente, pode permitir que o primeiro desfrute de algum benefício do tipo monopolístico. (ZYLBERSZTAJN, 1995, p. 17).

Nessa linha de pensamento, Breitenbach (2012) destaca o oportunismo como sendo uma vantagem de obtenção de informações antes da consolidação de um contrato, nos seguintes termos:

O oportunismo pré-contratual é um problema associado à presença de assimetria de informações. Surge como consequência do fato de alguns agentes econômicos deterem informação privada antes de se decidirem pela realização de um contrato com outro agente, sendo que tal informação é do interesse desse agente. (BREITENBACH, 2012, p. 78).

Como já relatado anteriormente, a escala de diferencial oscila de 0 a 7 , significando dificilmente e facilmente como pontos extremos, buscando assim compreender os níveis de aproximação dos participantes da pesquisa com relação ao oportunismo. O agricultor foi questionado se mudaria de laticínio se fosse ofertado cinco centavos a mais por litro de leite por outra empresa (Quadro 2).

Quadro 2 - Reação dos agricultores a uma oferta de R\$ 0,05 a mais pelo litro do leite por outra empresa

\begin{tabular}{|c|c|c|}
\hline Escala de diferencial & Número de agricultores & Porcentagem \\
\hline Dificilmente & & $51,72 \%$ \\
\hline 0 & 90 & $4,02 \%$ \\
\hline 1 & 7 & $7,47 \%$ \\
\hline 2 & 13 & $4,60 \%$ \\
\hline 3 & 8 & $14,95 \%$ \\
\hline 4 & 26 & $2,30 \%$ \\
\hline 5 & 4 & $2,30 \%$ \\
\hline 6 & 4 & $12,64 \%$ \\
\hline 7 & 22 & \\
\hline Facilmente & & \\
\hline
\end{tabular}

Fonte: Pesquisa de campo, 2017. 
Destaca-se que em 51,72\% dos agricultores responderam que dificilmente iriam aceitar a proposta de trocar de laticínio por cinco centavos a mais por litro de leite, porém ressalta-se que os demais agricultores tiveram variações de posição, pois $62,64 \%$ dos agricultores mudaram de laticínio nos últimos três anos, o que coloca em maior dúvida o sentimento de uma nova troca de laticínio em um curto período de tempo. Também houve relatos dos participantes de que o aceite da proposta dependeria de qual laticínio realizaria a oferta, pois muitas empresas mantêm o valor ofertado por alguns meses e após este período acabam pagando o mesmo valor que o produtor já vinha recebendo antes de mudar de empresa.

Este jogo de mercado por parte da empresa, também foi constatado por Breitenbach (2008), onde afirma que as empresas realizam o pagamento do preço tratado com o produtor apenas nos primeiros meses e posteriormente, alegando motivos diversos, diminuem o preço pago, podendo vir a se igualar ao recebido pela empresa à qual o produtor entregava o produto anteriormente.

Durante a pesquisa muitos agricultores relatavam terem passado por uma situação de penalização imposta pelo laticínio ou conhecem alguém que passou por uma sanção. Segundo relatos dos agricultores, as sanções corriqueiras ocorrem em situações nas quais um produtor muda de laticínio, assim ele é penalizado pela empresa em que vinha atuando nos últimos meses, recebendo por sua produção já entregue um valor abaixo de mercado. Outra forma de sanção na quebra de contrato relatada é quando um produtor deixa de entregar sua produção a um laticínio. Algumas empresas deixam de aceitar este produtor no seu quadro de atuação de coleta de leite.

\section{Especificidade dos Ativos}

A especificidade dos ativos está atrelada ao uso de tecnologias específicas e especializadas para o desenvolvimento da atividade leiteira. Para Breitenbach (2012), a especificidade dos ativos está fortemente condicionada às características da base técnica, mas não se limita a elas. A especificidade dos ativos pode se alterar ao longo do tempo, à medida, por exemplo, que uma nova tecnologia surge.

A especificidade dos ativos está fortemente condicionada às características da base técnica, mas não se limita a elas. A especificidade dos ativos pode se alterar ao longo do tempo, à medida, por exemplo, que uma nova tecnologia 
surge, dissemina-se e amadurece. A especificidade tende a ser maior no início da trajetória tecnológica, exigindo, muitas vezes, a integração vertical. (BREITENBACH, 2012, p. 81).

Para Schubert (2012, p. 84), “dentre as dimensões da Economia dos Custos de Transição, a especificidade dos ativos é a de maior destaque, pois envolve a relação mais próxima, de fato, com a estrutura da firma, ou seja, o capital que está investido e que acaba envolvendo custos diretos".

Nessa mesma linha de pensamento, os autores Casali e Marion Filho (2012, p. 324) similarmente consideram a especificidade dos ativos "a mais importante, porque a sua existência pressupõe o uso de tecnologia especializada, investimentos não triviais, e se o ambiente é de racionalidade limitada e oportunismo".

Desse modo, conforme apresentado pelos autores, considera-se a especificidade dos ativos como sendo um dos custos mais relevantes na da Economia dos Custos de Transição- ECT, pois está relacionado diretamente ao capital investido para o desenvolvimento das atividades, podendo haver a necessidade de novos investimentos, como tecnologias, a fim de manter-se ativo no mercado.

Em especificidade dos ativos foram relacionadas questões que têm o intuito de analisar o capital que está investido na propriedade e se estes ativos poderiam ser utilizados em outras atividades. Dessa forma, 61,49\% dos agricultores participantes da pesquisa consideraram não possuir outra atividade na propriedade que pudesse ser desenvolvida com os equipamentos utilizados na atividade leiteira, conforme pode ser observado no Quadro 3. Isso ocorre devido a muitas propriedades possuírem vacas das raças Jersey ou Holandesas, específicas para a produção de leite, não obtendo altos potenciais genéticos para produção de carne.

Os agricultores manifestaram que poderiam desenvolver o beneficiamento do leite, produzindo na propriedade queijos e bebidas lácteas e, posteriormente, realizar a comercialização destes produtos. Contudo, consideram que os investimentos necessários para o beneficiamento do leite nas propriedades seria alto, necessitaria da construção de um espaço adequado para a produção e a aquisição de equipamentos. Outro empecilho encontrado pelos agricultores é a dificuldade de legalidade do processo de beneficiamento, muitos consideram a necessidade de comercialização nos Municípios 
vizinhos. Observou-se ainda, falta de estímulo por parte dos agricultores para investimento em ativos, devido ao preço que vem recebendo pelo litro de leite.

Quadro 3 - Possibilidade dos ativos serem utilizados em outra atividade na propriedade

\begin{tabular}{|c|c|c|}
\hline Escala de diferencial & Número de agricultores & Porcentagem \\
\hline Dificilmente & & \\
\hline 0 & 107 & $61,49 \%$ \\
\hline 1 & 1 & $0,57 \%$ \\
\hline 2 & 10 & $5,75 \%$ \\
\hline 3 & 6 & $3,45 \%$ \\
\hline 4 & 19 & $10,92 \%$ \\
\hline 5 & 8 & $4,60 \%$ \\
\hline 6 & 3 & $1,72 \%$ \\
\hline 7 & 20 & $11,50 \%$ \\
\hline Facilmente & & \\
\hline
\end{tabular}

Assim, destaca-se que na maior parte dos participantes da pesquisa, os custos de transação, no que se referem às especificidades dos ativos, possuem índices altos. Esse fator é determinado devido a muitos considerarem que apenas as terras e a mão de obra, onde desenvolvem a atividade leiteira, poderão ser utilizadas de outras formas na propriedade. No que diz respeito à forma como o leite é produzido, muitos consideram que o fator que mais eleva os custos de transação no item são os equipamentos e os animais usados na produção de leite.

\section{Frequência}

Já a frequência com que ocorre uma transação é de extrema importância na construção da reputação entre os envolvidos, pois diminui a relação de oportunismo entre os agentes. Conforme Schubert (2012), conforme a frequência com que as transações se repetem e os contratos se renovam, o comportamento oportunista tende a diminuir, visto que a necessidade ou o favorecimento dessas relações coíbe tal ação. Do mesmo modo, para Ilha (2010) quanto maior a recorrência em que se realizam as transações, mais alta é a probabilidade de afirmação de realizar contratos duradouros possuindo prazos mais longos. Desse modo, a frequência possibilita que os agentes identifiquem semelhanças entre as partes, colaborando para que não haja comportamento imprevisto. 
Segundo Arbage (2004, p. 84) "maior frequência nas transações entre os mesmos agentes gera o que se chama de reputação." Assim, com o aspecto de reputação criada entre os agentes de uma negociação tende a reduzir os custos de transação, pois os parceiros apresentam a necessidade de buscar informações comerciais e a qualidade do produto transacionado.

Nesta pesquisa, em 78\% das propriedades a coleta do leite é realizada a cada dois dias, enquanto em $16 \%$ é realizada todos os dias. As propriedades com maior produção não possuem resfriadores com capacidade de armazenagem para que o recolhimento do leite seja realizado em um período maior de tempo, já nas propriedades onde o recolhimento é realizado a cada quatro dias, deve-se à baixa quantidade de produção. Assim os laticínios julgam inviável a coleta ser realizada em um menor período de tempo. Assim, com a frequência do recolhimento do leite ser em um curto período de tempo, há a diminuição dos custos de transação.

\section{Confiança}

Para análise das relações de confiança entre o produtor e os agentes que fazem parte da cadeia produtiva do leite, foram realizadas oito perguntas, na escala de diferencial de zero a sete, os agricultores responderam conforme seu sentimento de confiança com os agentes dos laticínios.

Desta forma, os agricultores foram questionados quando à sua relação de confiança ao laticínio que atua na comercialização de sua produção leiteira, sendo constatado que $88,5 \%$ dos agricultores possuem um sentimento de confiança na escala de diferencial de cinco a mais; destes, 57,47\% têm total confiança aos laticínios, de acordo com o Quadro 4.

Os altos níveis de relação de confiança entre os agricultores e os laticínios possibilitam uma redução dos custos de transação, visto que, ao estabelecer um nível de confiança entre os agentes, podem-se assegurar contratos futuros e a não anulação de contratos vigentes. 
Quadro 4 - Escala diferencial da relação de confiança do agricultor em relação ao laticínio

\begin{tabular}{|c|c|c|}
\hline Escala de diferencial & Número de agricultores & Porcentagem \\
\hline Não confiável & & $0,00 \%$ \\
\hline 0 & 0 & $0,57 \%$ \\
\hline 1 & 1 & $1,73 \%$ \\
\hline 2 & 3 & $1,73 \%$ \\
\hline 3 & 3 & $7,47 \%$ \\
\hline 4 & 13 & $14,94 \%$ \\
\hline 5 & 26 & $16,09 \%$ \\
\hline 6 & 28 & $57,47 \%$ \\
\hline 7 & 100 & \\
\hline Confí́vel & & \\
\hline
\end{tabular}

Fonte: Pesquisa de campo, 2017.

Em respeito à relação de confiança ao freteiro que "puxa" o leite, 95,99\% dos agricultores responderam na escala de diferencial de cinco a mais, sendo que $81,04 \%$ relataram ter total confiança, como pode ser observado no Quadro 5.

Quadro 5 - Escala diferencial de relação de confiança do agricultor em relação ao que transporta o leite

\begin{tabular}{|c|c|c|}
\hline Escala de diferencial & Número de agricultores & Porcentagem \\
\hline Não confiável & 1 & $0,57 \%$ \\
\hline 0 & 0 & $0,00 \%$ \\
\hline 1 & 1 & $0,57 \%$ \\
\hline 2 & 0 & $0,00 \%$ \\
\hline 3 & 5 & $2,87 \%$ \\
\hline 4 & 10 & $5,75 \%$ \\
\hline 5 & 16 & $9,20 \%$ \\
\hline 6 & 141 & $81,04 \%$ \\
\hline 7 & & \\
\hline Confiável & & \\
\hline
\end{tabular}

Fonte: Pesquisa de campo, 2017.

Pode-se dizer que as variáveis que interferem nos custos de transação que ocorrem na atividade leiteira no município de Caiçara, ocorrem devido às incertezas que são causados pelo desconhecimento do comportamento dos agentes nas negociações e especificidade dos ativos, pois os agricultores, na sua maioria, relataram não possuírem outra atividade rentável a ser desenvolvida na propriedade com os equipamentos e o gado leiteiro.

Desta forma, a fim de minimizar os Custos de Transação intrínsecos no mercado do leite da agricultura familiar no município de Caiçara - RS, sugere-se a criação de 
eventos (palestras, dia de campo, reuniões etc.) com o intuito de aproximação entre os agentes e o estabelecimento de contratos formais nas transações da atividade leiteira.

\section{Considerações finais}

Com o propósito de esclarecer os comportamentos e as estruturas de governanças entre os produtores familiares que atuam na atividade leiteira e indústrias processadoras, neste estudo, foram utilizadas as teorias da Nova Economia Institucional (NEI) e da Economia dos Custos de Transação (ECT). A NEI possibilitou uma análise do ambiente institucional e conceitua as regras formais e informais encontradas no mercado do leite.

A ECT proporcionou uma maior análise das transações e das estruturas de governança, sendo possível a identificação das estruturas de mercado, comportamento dos agentes econômicos em um ambiente competitivo. As bases teóricas permitiram a compreensão das estratégias dos agentes nas transações na produção leiteira.

Ressalta-se que, durante o desenvolvimento da pesquisa a campo, foi realizada a visita aos produtores de leite de Caiçara em 30 localidades diferentes. Constatou-se uma redução na quantidade de propriedades familiares que atuam na atividade leiteira, pois segundo dados da Prefeitura Municipal o município contava com 316 estabelecimentos. Acredita-se que a pesquisa atingiu aproximadamente todas as propriedades familiares que atuam na atividade leiteira.

Entre as variáveis que que compõem os custos de transação na atividade leiteira no município de Caiçara-RS, de acordo com a Nova Economia Institucional, destaca-se que nas transações realizadas entre os agricultores participantes da pesquisa e laticínios, pode-se observar a falta de conhecimento por grande parte dos agricultores familiares no que se trata de políticas agrícolas, mudanças nas normativas e estatutárias dos laticínios, estratégias futuras do leite e informações sobre o valor que receberá pela produção já entregue à empresa, gerando incertezas neste mercado.

Do mesmo modo, destacam-se altos níveis de incertezas conductista por parte dos laticínios, que é causado pelos comportamentos oportunistas dos agricultores, criando desconhecimento por parte das empresas sobre o comportamento dos parceiros. No que tange ao oportunismo, destaca-se a ação dos laticínios em ofertar valores superiores ao de mercado aos agricultores com o intuito de atraí-los para a empresa e com o passar dos 
meses acabam reduzindo o valor pago pelo litro de leite, fazendo o produtor receber o equivalente ao que vinha recebendo pela antiga empresa.

A especificidade dos ativos é um fator determinante nos custos de transação, indicando que devem ser feitas melhorias na atividade desenvolvida, e a maior parcela dos participantes da pesquisa expressaram não possuir outra atividade rentável que possa ser realizada com os equipamentos e o rebanho de gado leiteiro, criando assim ao produtor uma barreira de saída.

Assim, no intuito de minimizar as incertezas, sugere-se ações que possibilitem maior aproximação entre os agentes do mercado do leite, podendo ser através de palestras, dia de campo no município de Caiçara e reuniões, com o objetivo de harmonizar a desigualdade de informações, obtendo um ambiente institucional com maior estabilidade.

A fim de minimizar as ações oportunistas criadas pelos laticínios no que tange à oferta ao produtor como os valores acima de mercado por litro de leite e as ações de incertezas conductista dos agricultores que atuam na atividade leiteira sobre os laticínios, é através da fixação de contratos formais que regulam as transações com cláusulas que detenham informações necessárias, de maneira que reduzam os custos de transação exante e ex-post.

Por fim, com os contratos formais também será possível minimizar as especificidades dos ativos, pois criará uma maior relação de dependência do laticínio ao produtor por matéria prima, gerando ao agricultor a possibilidade de diluição dos custos de transações em um maior período, atuando em um mercado mais estável.

\section{Referências}

ARBAGE, A. P. Custos de transação e seu impacto na formação e gestão da cadeia de suprimentos: estudo de caso em estruturas de governança híbridas do sistema agroalimentar do Rio Grande do Sul. 2004. 280 f. Tese (Doutorado em Administração). Universidade Federal do Rio Grande do Sul, Porto Alegre, 2004.

BRASIL. Lei no 11.326, de 24 de julho de 2006. Diário Oficial da República Federativa do Brasil, Brasília, DF, 25 de jul. 2006. p. 1, col. 2. Disponível em: $<$ http://legis.senado.leg.br/legislacao/ListaTextoSigen.action?norma=572111\&id=1436 0147\&idBinario=15732147> . Acesso em: nov. 2017.

BREITENBACH, R. Estruturas de Mercado de Fatores e Governança na Cadeia Produtiva do Leite: Um Estudo de Caso do Munícipio de Ajuricaba - RS. 2008. 114 f. 
Dissertação. (Mestrado em Extensão Rural). Universidade Federal de Santa Maria, Santa Maria - RS, 2008.

BREITENBACH, R. Estrutura, conduta e governança na cadeia produtiva do leite: um estudo multicaso no Rio Grande do Sul. Santa Maria - RS. READ. Rev. eletrôn. adm. (Porto Alegre) [online]. vol.21, n.3, 2015. Disponível em: < http://www.scielo.br/scielo.php?>. Acesso em: nov. 2017

BUENO, N. P. Lógica da Ação Coletiva, Instituições e Crescimento Econômico: Uma Resenha Temática sobre a Nova Economia Institucional. Revista Econômica, jul. 2004, p. 11.

CASALI, M. S; MARION FILHO, P. J. .Custo de transação e governança na produção de leite em Cruz Alta (RS). Revista de Economia e Administração, v. 11, n.3, p. 321 341, jul/set. 2012.

COASE, R.H. The Nature of the Firm. Econômica, nov. 1937

FIGUEIREDO, J.C; MENDES, K; MICHELS, I. L. A Nova Economia Institucional e sua Aplicação no Estudo do Agronegócio Brasileiro. 2009. Disponível em:

<http://www.rea.ufv.br/index.php/rea/article/view/135/138>. Acesso em: nov. 2017.

ILHA, V. T. A Teoria dos Custos de Transação e o Modelo de Comercialização de Energia Elétrica Após as Reformas do Setor Elétrico. Porto Alegre - Julho, 2010.

INSTITUTO BRASILEIRO DE GEOGRAFIA E ESTATÍSTICA (IBGE) - Censo Agropecuário de 2006. Disponível em: <www.ibge.gov.br>. Acesso em: abr. 2017.

INSTITUTO BRASILEIRO DE GEOGRAFIA E ESTATÍSTICA (IBGE) - Censo Demográfico de 2010. Disponível em: 〈www.ibge.gov.br〉. Acesso em: nov. 2017.

PREFEITURA MUNICIPAL DE CAIÇARA/RS. Disponível em: <http://caicara.rs.gov.br/municipio/dados/>. Acesso em: nov. 2016.

ROSA, F. S; VAILATTI, J. L; VICENTE, E. F. R. A teoria Institucional Aplicada à Contabilidade Gerencial: Análise da Contribuição Teórica e Metodológica de Publicações Internacionais Ocorridas no Período de 2006 a 2015*. Florianópolis SC, 2017, p. 102.

SCHUBERT, M. N. Análise dos Custos de Transação nas Cooperativas de Produção de Leite no Oeste de Santa Catarina. Organizações Rurais \& Agroindustriais, Lavras, v. 16, n. 4 (edição especial), p. 435-449, dez. 2012.

TIMM, C. K. Critérios competitivos da produção de queijos: um estudo de caso na cooperativa agroindustrial pomerano alimentos. Pelotas - RS, 2012, 56 f.. Trabalho de Conclusão de Curso (Graduação em Administração) - Universidade Federal de Pelotas. Pelotas-RS, 2012. 
TOMÉ, L. H. P; SCHMIDT, C. M. Estruturas de governança na agroindústria canavieira paranaense: uma análise sob a ótica da nova economia institucional. Revista de Economia e Agronegócio. 2015, V.13, n. 1. Disponível em: <http://www.revistarea.ufv.br/index.php/rea/article/view/284/259>. Acesso em: $13 \mathrm{de}$ novembro de 2017.

WILLIANSON, O.E. The economic institutions of capitalism. The Free Press, New York, 1985.

ZYLBERSZTAJN, D. Estruturas de governança e coordenação do agribusiness: uma aplicação da nova economia das instituições. 1995. 241 f. Tese (Livre Docente em Administração) - Faculdade de Economia, Administração e Contabilidade, Universidade de São Paulo, São Paulo. São Paulo - SP, 1995.

Recebido em 20/12/2018.

Aceito para publicação em 16/04/2019. 